\title{
Fenologia reprodutiva de Tapirira guianensis na Reserva Natural Salto Morato - Guaraqueçaba, PR
}

\author{
Franciane Feltz Pajewski ${ }^{1 *}$, Andressa Tres ${ }^{1}$, Jaçanan Eloisa de Freitas Milani ${ }^{2}$, Alexandre Behling ${ }^{1}$, Alexandre \\ França Tetto ${ }^{1}$
}

${ }^{1}$ Universidade Federal do Paraná, Avenida Prefeito Lothário Meissner, 632, Jardim Botânico, Curitiba - PR, 80210-170

${ }^{2}$ Universidade Federal do Mato Grosso, Rua Fernando Corrêa da Costa, 2367, Boa Esperança, Cuiabá - MT, 78068-600

*Autor para correspondência: franpajewski@yahoo.combr

Recebido: Julho 2019/ Aceito: Novembro 2019/ Publicado: 31 Dezembro 2019

\section{Resumo}

Levando em consideração a importância de Tapirira guianensis Aubl. para a fauna e que estudos de fenologia dessa espécie foram na sua maioria desenvolvidos em ambientes aluviais, o objetivo do estudo foi avaliar a fenologia reprodutiva de $T$. guianensis em um remanescente de Floresta Ombrófila Densa submontana em Guaraqueçaba - PR e correlacionar os eventos fenológicos com as variáveis meteorológicas. As informações fenológicas foram coletadas mensalmente de junho de 2017 a maio de 2018. A fenologia foi observada com base no índice de intensidade de Fournier adaptado. Buscando verificar os períodos de ocorrência, pico e duração de cada fenofase foram realizadas análises estatísticas circulares. As fenofases foram correlacionadas com as variáveis meteorológicas, por meio da correlação de Spearman e da análise fatorial. Os resultados mostraram que botões florais e antese foram eventos sazonais, sendo que os botões ocorreram nos meses de agosto e setembro e a antese em setembro. Os frutos imaturos foram observados de outubro a janeiro, enquanto os frutos maduros de outubro a fevereiro. Não foram detectadas correlações entre as variáveis meteorológicas e as fenofases de floração. Para as fenofases de frutificação, foram observadas correlações positivas com temperatura máxima e fotoperíodo, e ainda, com precipitação, para os frutos maduros. Conclui-se que a floração esteve mais relacionada com fatores endógenos e atividade dos agentes polinizadores do que com as variáveis meteorológicas, enquanto a frutificação teve influência da temperatura e do fotoperíodo.

Palavras-chave: fenofases; variáveis meteorológicas; cupiuva; floração; frutificação.

\section{Abstract}

Taking into account the importance of Tapirira guianensis Aubl. to the fauna and that phenology studies were mainly developed in alluvial environments, the objective of this study was to evaluate the reproductive phenology of $T$. guianensis in the submontane Atlantic Rainforest in Guaraqueçaba - PR and to correlate the phenological events with the meteorological variables. Phenological data were monthly collected during the period from June 2017 to May 2018 and observed according to the adapted Fournier intensity index. In order to verify the periods of occurrence, peak and duration of each phenophases, we performed circular statistical analysis. Phenophases were correlated with the meteorological variables, using Spearman correlation and factorial analysis. The results showed that flower buds and anthesis were seasonal events, with the buds occurring in the months of August and September and the anthesis in September. The immature fruits were observed from October to January, while the ripe fruits from October to February. No correlation was detected between the meteorological variables and the flowering phenophases. For the fruiting phenophases, positive correlations were observed with maximum temperature and photoperiod, and also, with precipitation, for mature fruits. It was concluded that flowering was more related to endogenous factors and activity of pollinating agents than to meteorological variables, while fruiting was influenced by temperature and photoperiod.

Keywords: phenophases; meteorological variables; cupiuva; flowering; fruiting.

\section{Introdução}

Informações fenológicas são importantes para estudos como o de fisiologia e revisão taxonômica (Morellato et al. 2000; Martini et al. 2010), permitem compreender as relações entre as plantas, seus polinizadores e seus dispersores (Cascaes et al. 2013), geram dados que subsidiam a recuperação de áreas degradadas e o manejo de unidades de conservação (Rego e Lavaronti 2007; Milani et al. 2013) e são utilizadas como ferramenta de monitoramento das oscilações climáticas, uma vez que o comportamento fenológico das plantas é muito sensível às condições do clima (Kuplich et al. 2013).

A fenologia pode ser subdividida em vegetativa (estudo das folhas) e reprodutiva (composta pela floração e frutificação das plantas). O evento de floração é importante para a organização e a estrutura de comunidades vegetais, a conservação dos polinizadores e a manutenção dos serviços ecossistêmicos (Morellato et al. 2016); enquanto a frutificação tem maior importância e relação com a fauna de vertebrados, especialmente de aves e mamíferos (Hawes e Peres 2014).

Dentre os fatores ambientais que regulam os eventos fenológicos reprodutivos estão as variáveis meteorológicas, sendo que, em geral, plantas de florestas tropicais de clima sem sazonalidade climática pronunciada respondem a estímulos meteorológicos diferentes daquelas de clima sazonal. Destacando-se para a primeira situação temperatura e fotoperíodo e no segundo caso, precipitação, déficit hídrico e temperatura (Morellato et al. 2000; Talora e Morellato 2000).

A espécie Tapirira guianensis, popularmente conhecida como pau-pombo, cupiuva-vermelha, fruto-de-pombo e cupiuva, é considerada perenifólia, pioneira e heliófila e pode atingir até $30 \mathrm{~m}$ de altura (Lorenzi 1998; Carvalho 2006). As flores, segundo Lenza e Oliveira (2005), são unissexuais em plantas dióicas, contudo, ocasionalmente há presença de flores hermafroditas em matrizes femininas. Quanto ao fruto, é uma drupa ovoide de coloração verde quando imaturo e coloração roxa quando maduro. 
A síndrome de polinização é por zoofilia e de acordo com Lenza e Oliveira (2005) essa espécie é dependente dos agentes polinizadores, uma vez que na sua ausência a produção de frutos é baixa. A síndrome de dispersão é essencialmente zoocórica, sendo feita por aves das famílias Columbideae, Tyrannidae, entre outras e ainda por mamíferos, como macaco-bugio, mono-carvoeiro e sagui (Carvalho 2006).

Estudos fenológicos com a espécie $T$. guianensis foram desenvolvidos principalmente em ambientes de restinga, cerrado, brejos de altitude e floresta aluvial (e.g. Locatelli e Machado 2004; Lenza e Oliveira 2005; Santana et al. 2009; Santos e Ferreira, 2013), não havendo até o presente momento estudos fenológicos da espécie em ambiente submontano.

Tendo em vista o exposto, o presente estudo teve como objetivo determinar a fenologia reprodutiva desta espécie em um remanescente de Floresta Ombrófila Densa (FOD) em Guaraqueçaba - PR e correlacionar os eventos fenológicos com as variáveis meteorológicas.

\section{Material e Métodos \\ Caracterizacão da área de estudo}

A área de estudo está localizada na Reserva Natural Salto Morato (RNSM), nas coordenadas $25^{\circ} 09^{\prime} 45^{\prime \prime} \mathrm{S}$ e $48^{\circ} 18^{\prime} 10^{\prime \prime}$ W, situada no município de Guaraqueçaba - Paraná (Figura 1). A RNSM possui uma área de $2.252,83$ ha e apresenta altitudes que oscilam, em média, de 150 a $400 \mathrm{~m}$, sendo a cota superior de $900 \mathrm{~m}$ e a inferior de $20 \mathrm{~m}$ (Fundação Grupo Boticário de Proteção à Natureza (FGBPN) 2011).
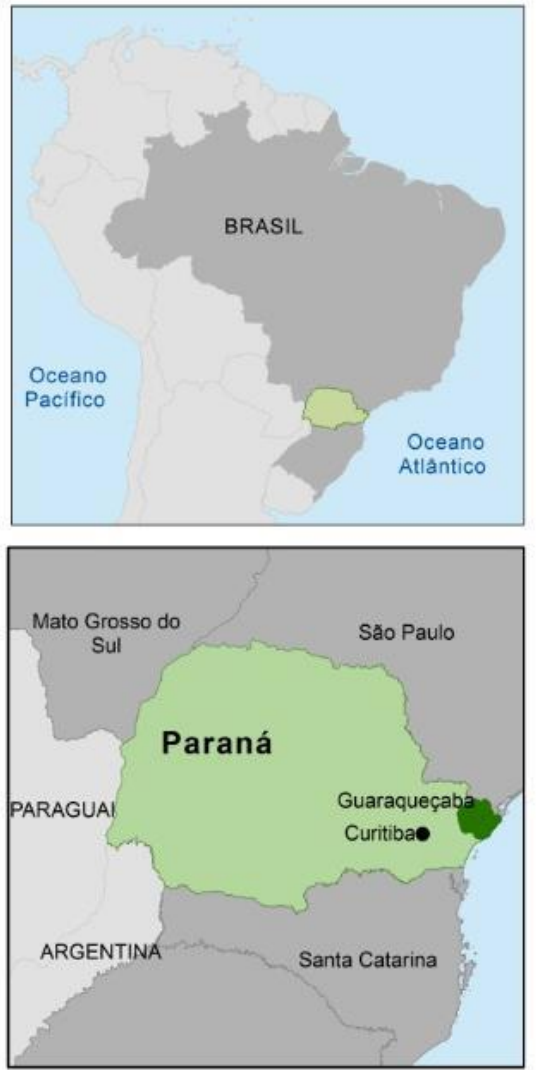

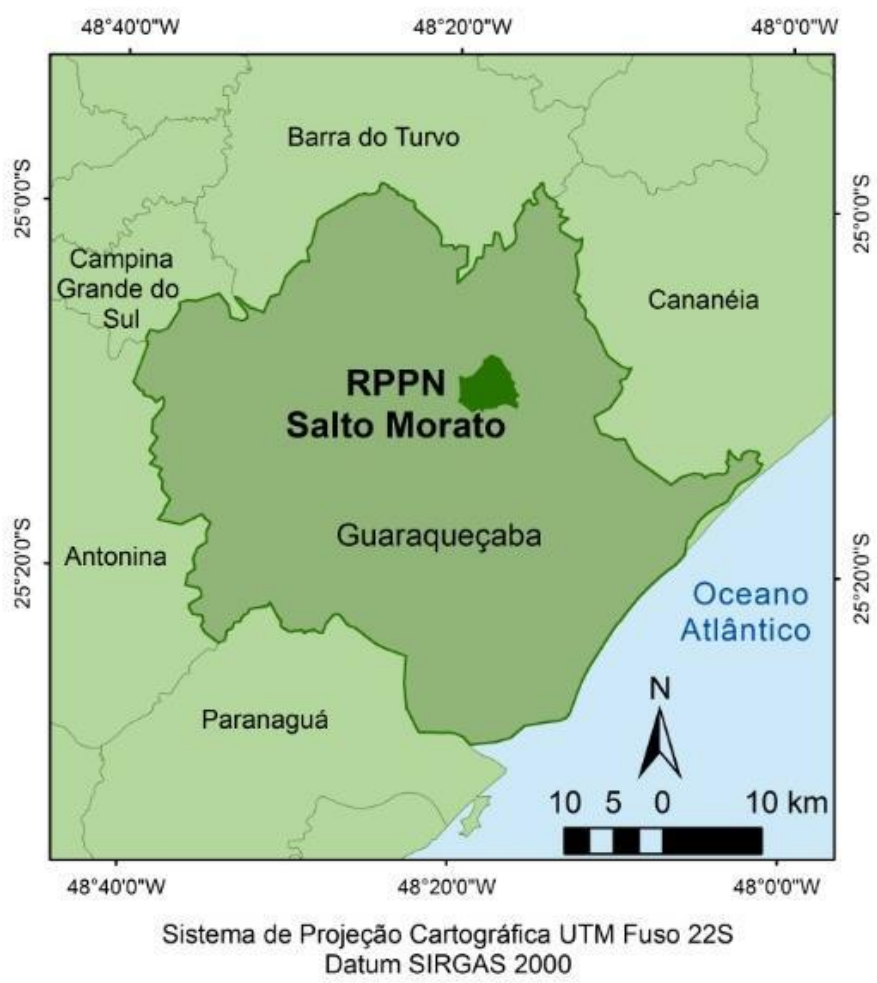

Datum SIRGAS 2000

Figura 1. Localização da área de estudo. Fonte: Instituto Brasileiro de Geografia e Estatística (IBGE 2016), adaptado pelos autores (2019).

De acordo com Alvares et al. (2013), toda a região costeira do Paraná, incluindo Guaraqueçaba, encontra-se no tipo climático Cfa segundo a classificação climática de Köppen. Este tipo climático é caracterizado por ser subtropical úmido, com verões quentes, geadas pouco frequentes, sem estação seca definida e com tendência de concentração de chuvas nos meses de verão (Soares et al. 2015).

As formações vegetais existentes na RNSM incluem-se nos domínios da FOD, nas variações aluvial, submontana, montana e altomontana. Quanto ao desenvolvimento da floresta, existem na reserva formações que variam desde floresta primária pouco alterada a formações típicas da sucessão secundária, nas fases inicial, intermediária e tardia (FGBPN 2011). Os indivíduos de T. guianensis estudados (Figura 2) estão em áreas de FOD submontana primária pouco alterada na altitude média de $350 \mathrm{~m}$.

\section{Coleta de dados meteorológicos}

Para os dados de temperatura $\left({ }^{\circ} \mathrm{C}\right)$ e umidade relativa $(\%)$ o aparelho registrador utilizado foi do tipo $\mathrm{HOBO} \mathrm{H} 21$ micro station com sensor S-THB (Figura 3a). Esta estação foi instalada no interior da floresta, próxima aos indivíduos de $T$. guianensis, e os dados foram coletados de hora em hora durante o período do estudo. O sensor utilizado apresenta uma margem de erro de $\pm 0,21{ }^{\circ} \mathrm{C}$ para temperatura e $\pm 2,5 \%$ para umidade. A estação meteorológica foi fixada em tubos de PVC, a 1,20 m do solo.

Os dados de precipitação $(\mathrm{mm})$ e radiação solar $\left(\mathrm{W} / \mathrm{m}^{2}\right)$ foram obtidos por meio da estação meteorológica do Sistema Meteorológico do Paraná (SIMEPAR) instalada no interior da reserva (Figura 3b) e o fotoperíodo obtidos de Soares et al. (2015).

\section{Coleta de dados fenológicos de T. guianensis}

As informações fenológicas foram coletadas mensalmente de junho de 2017 a maio de 2018 até o sétimo dia de cada mês, sendo os dados coletados referentes ao mês anterior da coleta. Foram selecionados sete indivíduos de $T$. 
Pajewski et al.

guianensis, com distância mínima entre si de $20 \mathrm{~m}$, para observação das seguintes fenofases reprodutivas: botões florais, antese, frutos imaturos e frutos maduros.

As observações consideraram o percentual de intensidade de Fournier adaptado por Milani (2013), que consiste na utilização de uma escala intervalar semiquantitativa de quatro categorias (0 a 3): 0 - ausência da fenofase; 1 - fenofase presente de 1 a $25 \%$ da copa; 2 fenofase presente de 26 a $50 \%$ da copa; e 3 - fenofase presente acima de $50 \%$ da copa. A porcentagem de intensidade tota foi calculada pela fórmula: ( $\Sigma$ Indice de Fournier $/\left(\mathrm{n}^{\circ}\right.$ indivíduos*3)) * 100 .

O material selecionado para identificação da espécie foi depositado no Herbário Escola de Florestas Curitiba (EFC), com número 16394.

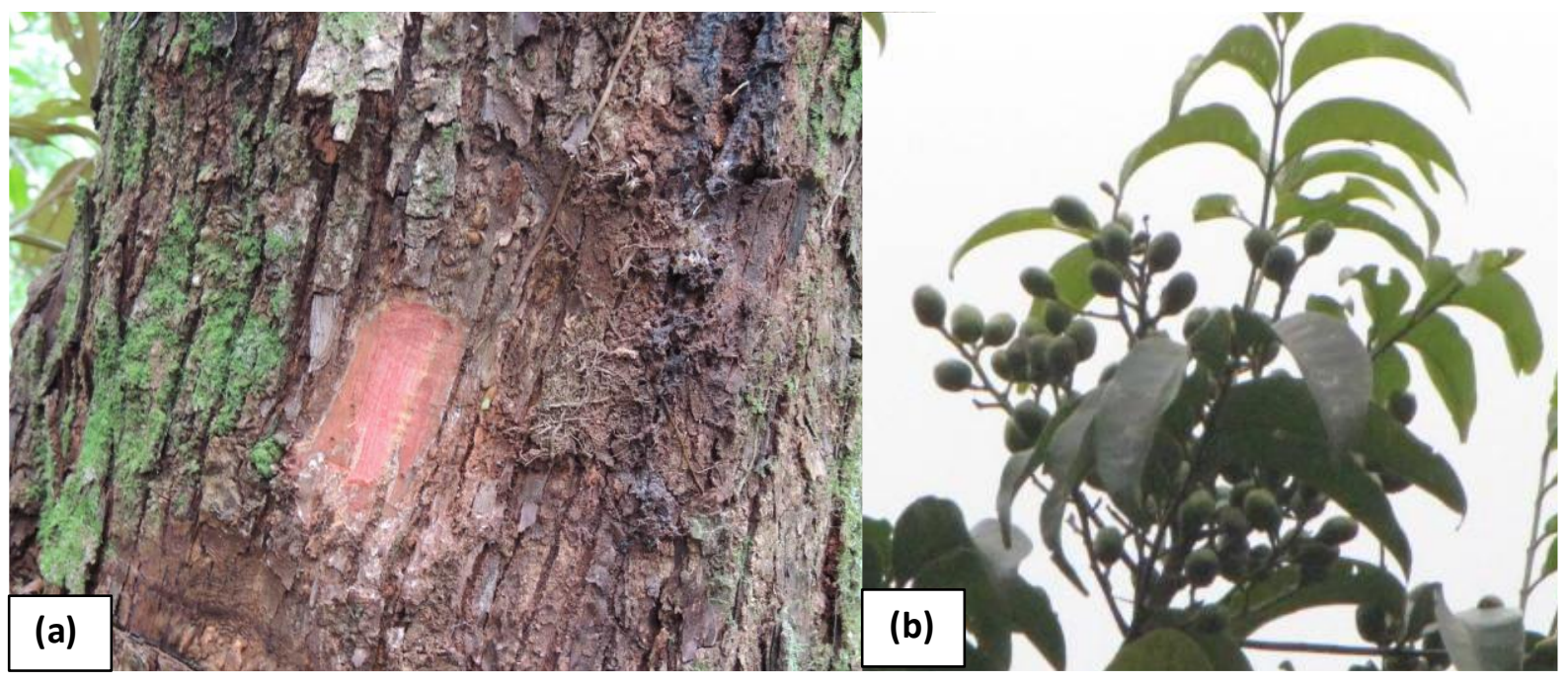

Figura 2. (a) casca interna; (b) detalhe dos frutos imaturos.

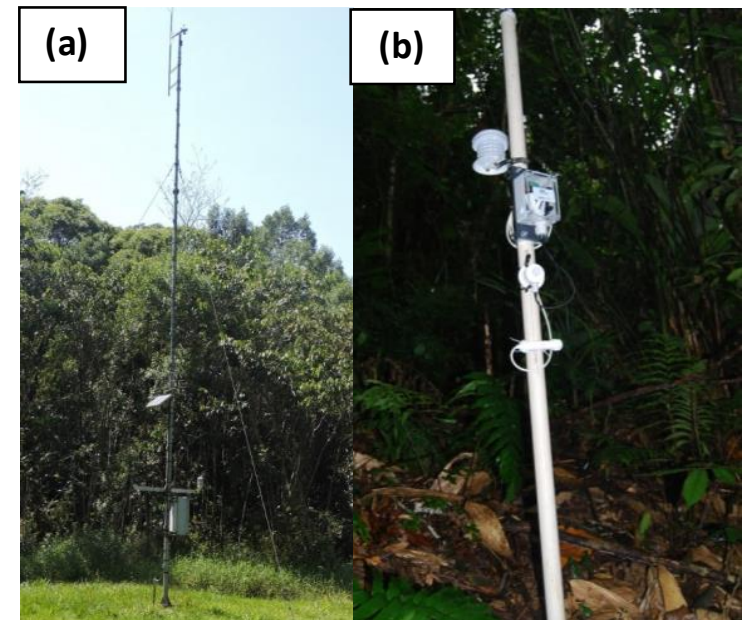

Figura 3. (a) estação meteorológica instalada no interior da floresta; (b) estação meteorológica automática do SIMEPAR.

\section{Análise dos dados}

A fim de verificar períodos de ocorrência, pico e duração de cada fenofase foram realizadas análises estatísticas circulares, utilizando o software ORIANA 4.

Nesse procedimento, os dias do ano $(0-365)$ são convertidos em graus $(0-360)$, para avaliar a ocorrência de sazonalidade nas fenofases estudadas, convertendo os meses do ano em ângulos. A partir desta transformação, foram obtidas as datas médias de ocorrência de cada fenofase, pela conversão das direções angulares médias em datas médias correspondentes, assim como o seu grau de sazonalidade. A data média corresponde à época do ano em que as datas de uma dada fenofase ocorreram para a maioria dos indivíduos (Talora e Morellato 2000) e o grau de sazonalidade é determinado pelo coeficiente de concentração (r), o qual varia de 0 (uniformidade da fenofase ao longo do ano) a 1 (fenofase concentrada em torno de uma única data ou época do ano).

A significância destas variáveis foi medida pelo teste Ray leigh (z) para distribuições circulares (testes realizados ao nível de $5 \%$ de probabilidade). Portanto, resultados de $\mathrm{z}$ maiores que 0,05 indicam ausência de direção e de sazonalidade e resultados de $\mathrm{z}$ menores que 0,05 indicam que há uma direção média significativa e, consequentemente, alguma sazonalidade da fenofase (Morellato et al. 2000).

Nos histogramas circulares, os valores mostrados no gráfico referem-se ao resultado do índice de intensidade; o início da marcação (zero graus) fica entre dezembro e janeiro; a direção da seta aponta a data média da distribuição de frequências; e o comprimento da seta indica a concentração dos indivíduos em torno dessa data, sendo quanto maior a seta, maior a concentração (Pirani et al. 2009).

A ocorrência das fenofases foi correlacionada com as variáveis meteorológicas (temperaturas máxima, média e mínima, umidade relativa do ar, fotoperíodo, radiação solar e precipitação) por meio da correlação de Spearman, sendo que os resultados foram classificados conforme segue: muito baixa $=|0,00|-0,20 \mid$; baixa $=|0,20|-0,40 \mid$; moderada $=$ $|0,40 \vdash 0,60|$; alta $=|0,60+0,80|$; muito alta $=\mid 0,80$ H $1,0 \mid$. As correlações foram consideradas significativas ao nível de $5 \%$ de probabilidade.

Por fim, foi realizada a análise fatorial, com intuito de verificar a estrutura das correlações existentes entre as fenofases e os dados meteorológicos e condensar as informações contidas nas diversas variáveis observadas. Neste tipo de análise, as variáveis aleatórias são agrupadas de acordo com suas relações. Como resultado, são criados fatores, onde, dentro de cada fator as variáveis são altamente correlacionadas e entre eles as correlações são baixas (Hair et al. 2009; Field 2013). Para tal, foi utilizado o software IBM SPSS Statistics 22 - versão gratuita. 
A análise fatorial foi realizada pelo método dos componentes principais, com rotação ortogonal da matriz pelo método de varimax. As variáveis foram atribuídas à um único fator, com base no peso da correlação existente dessa variável com cada fator, exceto para as variáveis que apresentaram cargas fatoriais maiores ou igual a 0,4 para mais de um fator, tendo sido consideradas multidimensionais (Rodríguez et al. 2010).

A adequação do método foi testada pelo teste de KaiserMeyer-Olkin (KMO), onde valores acima de 0,50 podem ser aceitos, e pelo teste de esfericidade de Bartlett, cujo valor de $p$ deve ser menor que o nível de significância $\alpha=5 \%$ (Hair et al. 2009).

\section{Resultados e discussão \\ Dados meteorológicos}

A Figura 4 apresenta os dados de temperatura (médias, máximas e mínimas absolutas), precipitação, umidade relativa do ar, radiação solar e fotoperíodo, durante o período estudado.

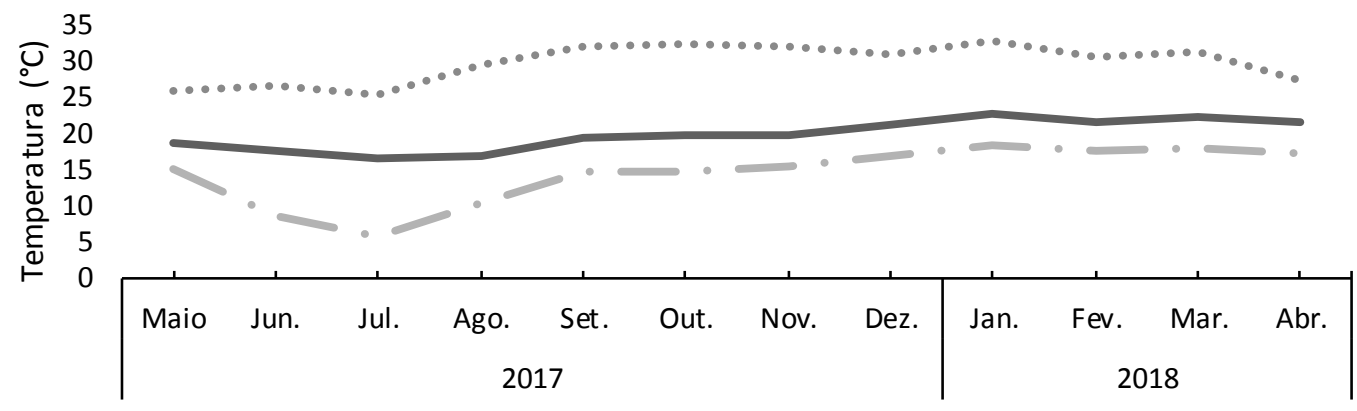

(a) T. média $\quad$-T. mínima .... T. máxima
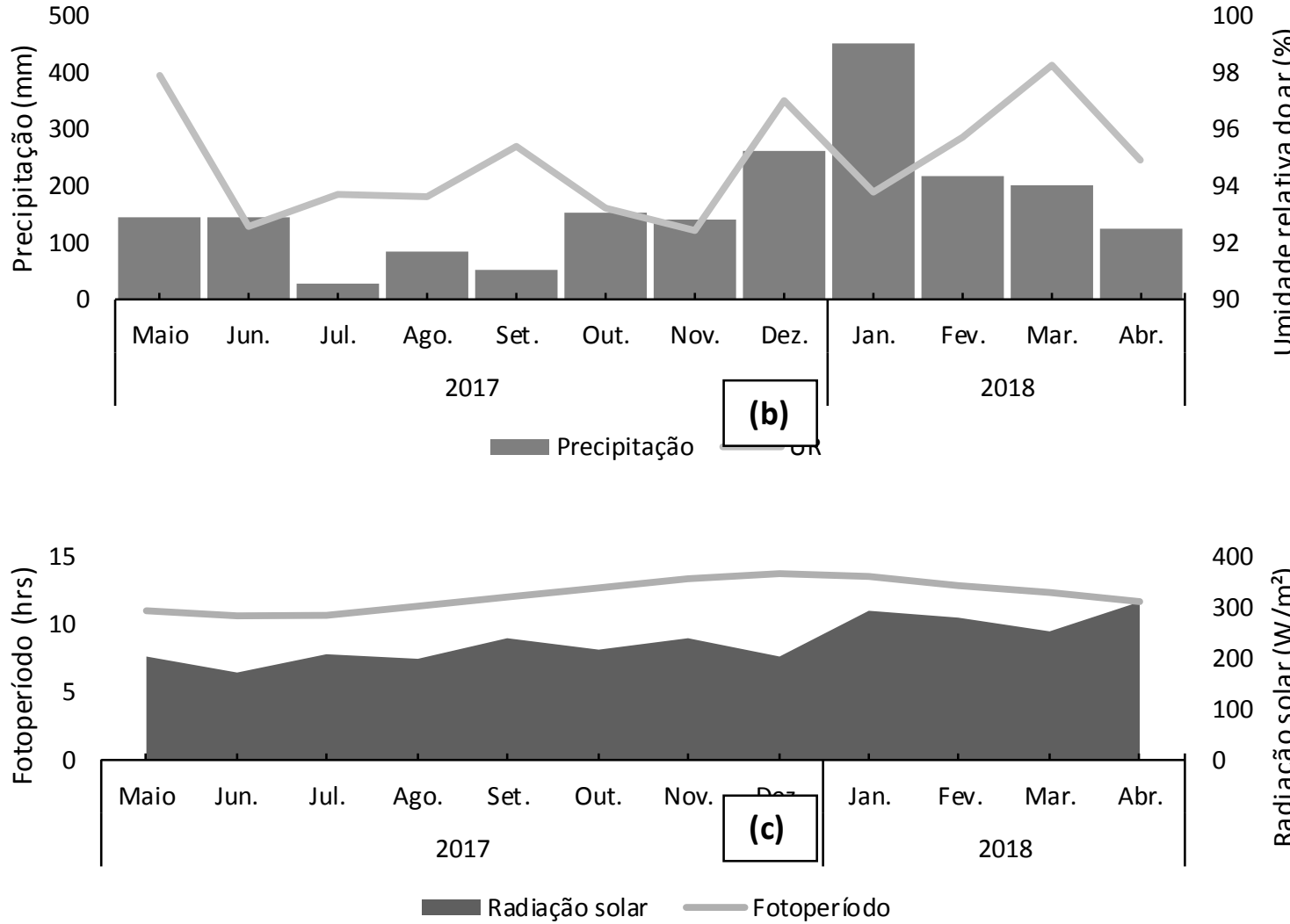

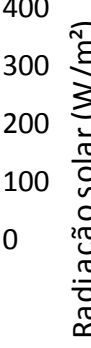

Figura 4. Comportamento das variáveis meteorológicas de maio de 2017 a abril de 2018: (a) temperatura média e temperatura máxima e mínima absoluta; (b) precipitação e umidade relativa do ar; (c) da radiação solar e do fotoperíodo.

De acordo com a Figura 4a, a média anual de temperatura registrada no interior da floresta foi de $19,5^{\circ} \mathrm{C}$, sendo que as maiores médias ocorreram nos meses de janeiro a março e as menores nos meses de junho a agosto. A temperatura mínima absoluta variou de 5,8 a $18,4{ }^{\circ} \mathrm{C}$, registradas no mês de julho e janeiro, respectivamente, enquanto a máxima absoluta variou de 25,4 a $32,9^{\circ} \mathrm{C}$, para os mesmos meses.
A Figura $4 \mathrm{~b}$ mostra que a precipitação total no período foi de $2.003 \mathrm{~mm}$, dos quais $56 \%$ (1.132 mm) se concentraram nos meses de dezembro a março. É provável que a precipitação anual tenha sido ainda maior, pois, após uma chuva de 190 
mm, no dia 11 de fevereiro de 2018, a estação do SIMEPAR apresentou uma falha e não registrou a precipitação por 22 dias seguidos. Ainda houve outros dias com falhas no registro de precipitação, totalizando 25 dias sem registros de precipitação. Em relação à umidade relativa do ar, essa variou de $92,4 \%$ no mês de novembro de 2017 a $98,3 \%$, no mês de março de 2018 .

Como observado na Figura 4c, os meses de janeiro a abril apresentaram as maiores médias de radiação solar durante o período analisado, chegando a uma radiação média de 310,1 $\mathrm{W} / \mathrm{m}^{2}$ no mês de abril. O mês de junho apresentou a menor radiação solar do período, com 169,6_W/ $/ \mathrm{m}^{2}$. Quanto ao fotoperíodo, observou-se que os meses de junho e julho tiverem os menores comprimentos do dia, com 10,6 e 10,7 horas, respectivamente, enquanto dezembro e janeiro tiveram os maiores comprimentos do dia, com 13,7 e 13,5 horas, respectivamente.

\section{Comportamento fenológico e correlações com variáveis meteorológicas}

Os resultados da análise circular indicaram que as fenofases de floração demonstraram ser mais concentradas, chegando ao valor de um para antese (Tabela 1). Para a frutificação, os coeficientes de vetor médio mostram que os frutos imaturos apresentaram maior concentração quando comparados aos frutos maduros, indicando que esses permaneceram por mais tempo nos indivíduos. As datas médias verificadas foram significativas (teste Rayleigh, $\mathrm{p}<$ $0,05)$ para todas as fenofases, o que indica que houve sazonalidade de todos os eventos fenológicos analisados (Pirani et al. 2009).

Tabela 1. Resultados da análise circular da fenologia para os indivíduos de Tapirira guianensis.

\begin{tabular}{ccccc}
\hline Fenofase & $\begin{array}{c}\text { Angulo } \\
\text { médio } \\
(\mu)\end{array}$ & $\begin{array}{c}\text { Data } \\
\text { média }\end{array}$ & $\begin{array}{c}\text { Vetor } \\
\text { médio } \\
(\mathrm{r})\end{array}$ & $\begin{array}{c}\text { Teste de } \\
\text { Rayleigh } \\
(\mathrm{p})\end{array}$ \\
\hline Botões florais & $231,904^{\circ}$ & $19 /$ ago. & 0,987 & $<1 \mathrm{E}-12$ \\
Antese & $255,000^{\circ}$ & $14 / \mathrm{set}$. & 1 & $<1 \mathrm{E}-12$ \\
Frutos imaturos & $314,639^{\circ}$ & $10 / \mathrm{nov}$. & 0,904 & $<1 \mathrm{E}-12$ \\
Frutos maduros & $350,401^{\circ}$ & $16 / \mathrm{dez}$. & 0,827 & $<1 \mathrm{E}-12$ \\
\hline
\end{tabular}

Os botões florais da espécie apareceram predominantemente no mês de agosto, se estendendo até setembro. A antese foi observada no mês de setembro (Figura 5). Lenza e Oliveira (2005), acompanhando a fenologia reprodutiva por três anos, em Uberlândia (MG), encontraram diferentes períodos de floração para a espécie. Nos meses de outubro e novembro no primeiro ano de estudo, outubro no segundo ano e no terceiro ano foram observados cinco picos de floração, sendo em agosto, setembro, outubro, novembro e dezembro. No estado de Sergipe, Santana et al. (2009) coletaram a espécie com flores abertas de novembro a janeiro. Santos e Ferreira (2013), também em Sergipe, encontraram floração em dois períodos distintos, variando de outubro a maio.

Foi possível observar que todos os indivíduos de $T$. guianensis tiveram a abertura das flores no mesmo mês. Esse sincronismo é uma forma da planta para atrair um maior número de visitantes florais, aumentando o transporte de pólen entre plantas e facilitando a polinização cruzada. Além do exposto, em espécies dióicas, como $T$. guianensis, a sincronia de floração entre os indivíduos de sexos opostos também tem um papel importante na polinização, pois, caso houvesse uma grande separação temporal na ocorrência das flores masculinas e femininas, o fluxo de pólen entre eles poderia ser comprometido (Lenza e Oliveira, 2005; Cobra et al. 2015).

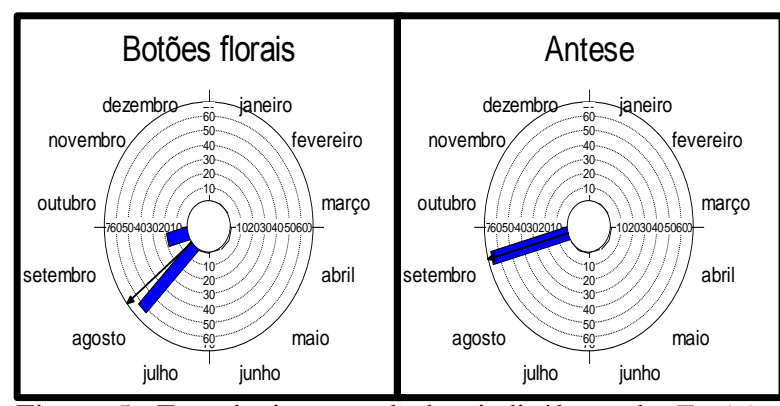

Figura 5. Frequência mensal dos indivíduos de Tapirira guianensis nas fenofases de floração, de maio de 2017 a abril de 2018.

Não foi encontrada correlação entre as fenofases de floração com as variáveis meteorológicas, mas foi possível notar que essas fenofases ocorreram em meses de menor precipitação. Locatelli e Machado (2004), em estudo em brejos de altitude de Pernambuco, e Santos e Ferreira (2013), em estudo no Sergipe, embora não tinham apresentado dados estatísticos de correlações das fenofases com dados meteorológicos, também encontraram para a espécie o período de floração nas estações mais secas do ano, para as regiões estudadas.

Para florestas tropicais é comum que o pico de floração se dê na estação úmida (Bianchin et al. 2016). Sendo assim, a diferença na época de floração encontrada nos estudos e a falta de correlação com as variáveis meteorológicas representam que essas fenofases podem estar mais relacionadas com fatores endógenos, como filogenia e às pressões seletivas bióticas como herbivoria, predação, competição e atividade dos agentes polinizadores e dispersores, do que com os elementos do clima, como abordado por Santos e Ferreira (2013).

Dos sete indivíduos avaliados, dois deles não apresentaram frutificação, o que indica que esses indivíduos provavelmente eram do sexo masculino. Em referência aos indivíduos que apresentaram frutificação, os frutos imaturos surgiram em outubro durando até o mês de janeiro. Por sua vez, os frutos maduros foram observados no mês de outubro, mas em pequena quantidade, se estendendo até fevereiro (Figura 6). A diferença entre a data média dessas fenofases foi de cerca de um mês.

Lenza e Oliveira (2005) observaram a frutificação em um período maior que o do presente estudo, com início em outubro e se estendendo até março, assim como Santos e Ferreira (2013), que encontraram frutificação com início em dezembro e finalizando em julho, com maturação dos frutos no período chuvoso da região.

As fenofases de frutificação apresentaram correlação positiva com temperatura máxima $(0,69$, tanto para frutos imaturos quanto para frutos maduros, $\mathrm{p}<0,05)$, fotoperíodo $(0,71$, para frutos imaturos e 0,88 para maduros, $p<0,01)$ e precipitação $(0,67$, para frutos maduros, $\mathrm{p}<0,05)$. Nota-se que a temperatura máxima e o fotoperíodo, aliado a fatores intrínsecos da espécie, são as variáveis responsáveis por desencadear o surgimento de frutos imaturos. Para frutos maduros, além dessas variáveis, observa-se também a influência da precipitação. De acordo com Milani (2013), os frutos maduros são resultado do amadurecimento dos frutos verdes, mas o que regula e intensifica os processos de maturação são os fatores ambientais, em virtude disso se justifica os frutos maduros apresentarem correlação com a precipitação e frutos imaturos não. 


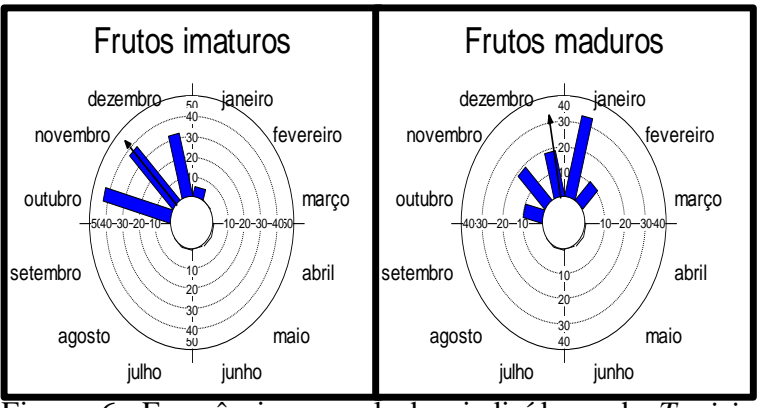

Figura 6. Frequência mensal dos indivíduos de Tapirira guianensis nas fenofases de frutificação, de maio de 2017 a abril de 2018.

Esses resultados vão ao encontro dos obtidos por Milani (2017), que estudando quatro espécies florestais em Floresta Ombrófila Densa aluvial no Paraná, encontrou o fotoperíodo como a variável de maior influência nas fenofases, sendo que a frutificação teve correlação significativa com fotoperíodo em todas as espécies. Ainda, segundo a autora, a temperatura é a segunda variável meteorológica que mais influência nas fenofases de forma geral.
Alencar et al. (1979), estudando 27 espécies da floresta tropical na Amazônia central, também encontraram correlações positivas entre a frutificação e a temperatura máxima, assim como Milani (2013) que destacou a importância da temperatura na formação dos frutos.

Em relação à análise fatorial, a matriz de cargas fatoriais, após a rotação ortogonal pelo método varimax, mostra que os dados foram resumidos em três grupos principais (Tabela 2). Esses grupos explicam $77,52 \%$ da variância total. Os valores das comunalidades, apresentados na Tabela 2, indicam que todas as variáveis foram bem representadas pelo componente principal no qual foram englobadas (Hair et al. 2009).

$\mathrm{O}$ primeiro grupo inclui as variáveis meteorológicas temperatura média e mínima, umidade relativa do ar, precipitação e radiação solar. As variáveis temperatura máxima e fotoperíodo, ainda que apresentem cargas fatoriais maiores no grupo dois, também têm influência na formação do grupo um. Dessa forma, pode-se notar que este grupo representa unicamente as variáveis meteorológicas e mostra a forte correlação existente entre elas.

Tabela 2. Matriz de cargas fatoriais após a rotação ortogonal pelo método varimax, para Tapirira guianensis

\begin{tabular}{c|c|c|c|c}
\hline \multirow{2}{*}{ Variável } & \multicolumn{3}{|c|}{ Componente } & \multirow{2}{*}{ Comunalidades } \\
\cline { 2 - 3 } & 1 & 2 & 3 & 0,970 \\
Temperatura média & 0,912 & & & 0,916 \\
Temperatura mínima & 0,902 & & & 0,603 \\
Umidade relativa & 0,641 & $-0,438$ & & 0,743 \\
Precipitação & 0,574 & 0,487 & $-0,421$ & 0,604 \\
Radiação solar & 0,770 & & & 0,934 \\
Temperatura máxima & 0,441 & 0,780 & & 0,945 \\
Fotoperíodo & 0,523 & 0,818 & & 0,690 \\
Fruto imaturo & & 0,801 & & 0,853 \\
Fruto maduro & & 0,825 & & 0,521 \\
Botão & & & 0,636 & 0,748 \\
Antese & & & 0,851 & - \\
\hline \% de variância & 33,57 & 29,60 & 14,35 & \\
\hline
\end{tabular}

Nota: foram suprimidas as cargas fatoriais inferiores a 0,4 Kaiser-Meyer-Olkin =0,511; Teste de Esfericidade de Bartlett $=$ $1110,448, p=0,000$.

O segundo fator é composto por duas variáveis do meio e duas variáveis fenológicas, sendo a temperatura máxima, fotoperíodo, fruto imaturo e fruto maduro. Como constatado na correlação de Spearman, essas variáveis meteorológicas são as que mais contribuem para a formação e maturação dos frutos de T. guianensis. A precipitação, mesmo que com menor carga fatorial, aparece na formação desse grupo, relação essa que também foi detectada na correlação de Spearman com os frutos maduros.

O terceiro grupo é formado unicamente pelas fenofases de floração: botão e antese, mostrando que essas fenofases são altamente correlacionadas, sendo que quanto maior a quantidade de botões florais, maior a quantidade de flores abertas. É possível observar a presença da precipitação no grupo 3 , indicando que existe certa correlação negativa entre os botões florais, antese e precipitação. Essa tendência também foi verificada por Santos e Ferreira (2013), mesmo que a correlação de Spearman nesse estudo não tenha apontado relação entre precipitação e as fenofases de floração.

Portanto, os resultados da análise fatorial corroboram os resultados obtidos pela correlação de Spearman, confirmam a importância do fotoperíodo e temperatura máxima na formação dos frutos e mostram a influência da precipitação pluviométrica em todas as fenofases reprodutivas de $T$. guianensis.

\section{Conclusões}

$\mathrm{O}$ estudo permitiu concluir que em ambiente submontano da Floresta Ombrófila Densa, a floração de Tapirira guianensis ocorreu nos meses de agosto e setembro de 2017, enquanto a frutificação teve início no mês outubro de 2017 e durou até fevereiro de 2018.

A floração de $T$. guianensis ocorreu nos períodos de menor precipitação, mas sua ocorrência parece estar mais relacionada com fatores endógenos e atividade dos agentes 
polinizadores, do que com as variáveis meteorológicas. A frutificação ocorreu nos meses mais chuvosos do ano e as variáveis temperatura máxima e fotoperíodo foram as que apresentaram maiores correlações com as fenofases de frutificação de $T$. guianensis.

\section{Agradecimentos}

Agradecemos ao Conselho Nacional de Desenvolvimento Científico e Tecnológico (CNPq), à Fundação de Pesquisas Florestais do Paraná (FUPEF) e à Fundação Grupo Boticário de Proteção à Natureza.

\section{Referências}

Alencar JDC, Almeida RAD, Fernandes, NP (1979) Fenologia de espécies florestais em floresta tropical úmida de terra firme na Amazônia Central. Acta Amazonica, 9(1):163-199.

Alvares CA, Stape JL, Sentelhas PC, Gonçalves JLM, Sparovek G (2013) Köppen's climate classification map for Brazil. Meteorologische Zeitschrift, 22(1):711-728. doi: 10.1127/0941-2948/2013/0507

Bianchin JE, Marques R, Britez RM, Capretz RL (2016) Deposição de fitomassa em formações secundárias na floresta atlântica do Paraná. Floresta e Ambiente, 23(4):524-533. doi: 10.1590/2179-8087.134015

Carvalho PER (2006) Espécies arbóreas brasileiras. v. 2, Brasília: Embrapa. 627p.

Cascaes MF, Citadini-Zanette V, Harter-Marques B (2013) Reproductive phenology in a riparian rainforest in the south of Santa Catarina state, Brazil. An. Acad. Bras. Ciênc, 85(4):1449-1460. doi: http://dx.doi.org/10.1590/0001-37652013105112

Cobra SSO, Nascimento F, Antoniazzi AS, Krause W, Silva CA (2015) Biologia reprodutiva de Cordiera macrophy lla (K. Schum.) Kuntze (Rubiaceae), espécie dioica da região sudoeste do estado de Mato Grosso, Brasil. Ceres, 62(6):516-523.

Fundação Grupo Boticário de Proteção à Natureza (FGBPN) (2011) Plano de manejo da Reserva Natural Salto Morato - Guaraqueçaba. v. 1. Curitiba. 222f.

Field A (2013) Discovering statistics using IBM SPSS Statistics. 4th Edition. Londres. 952p.

Hair JF, Black WC, Babin BJ, Anderson RE, Tatham RL (2009) Análise multivariada de dados. 6th Edition. Porto Alegre: Bookman. 688p.

Hawes JE, Peres CA (2014) Ecological correlates of trophic status and frugivory in neotropical primates. Oikos, 123(3):365-377. doi: https://doi.org/10.1111/j.16000706.2013.00745.x

Instituto Brasileiro de Geografia e Estatística (2016). Brasil: divisão político-administrativo. Rio de Janeiro.

Kuplich TM, Moreira A, Fontana DC (2013) Série temporal de índice de vegetação sobre diferentes tipologias vegetais no Rio Grande do Sul. Revista Brasileira de Engenharia Agrícola e Ambiental, 17(10):1116-1123. doi: http://dx.doi.org/10.1590/S1415-43662013001000014

Lenza E, Oliveira PE (2005) Biologia reprodutiva de Tapirira guianensis Aubl. (Anarcadinaceae), uma espécie dióica em mata de galeria do Triângulo Mineiro, Brasil. Revista Brasileira de Botânica, 28(1):180-190. doi: http://dx.doi.org/10.1590/S0100-84042005000100015
Locatelli EM, Machado IC (2004) Fenologia de espécies arbóreas de uma Mata Serrana (brejo de altitude) em Pernambuco, nordeste do Brasil. In: Porto KC, Cabral JJ, Tabarelli M. (Org.). Brejos de altitude em Pernambuco e Paraíba: história natural, ecologia e conservação. Brasília: Ministério do Meio ambiente, 1:255-276.

Lorenzi H (1998) Árvores brasileiras: manual de identificação e cultivo de plantas arbóreas nativas do Brasil. v. 1. Nova Odessa: Ed. Plantarum. 368p.

Martini A, Biondi D, Batista AC, Natal CM (2010) Fenologia de espécies nativas com potencial paisagístico. Semina: Ciências Agrárias, 31(1), 75-84.

Milani JEF (2013) Comportamento fenológico de espécies arbóreas em um fragmento de floresta ombrófila mista aluvial - Araucária, PR. Dissertação, Setor de Ciências Agrárias, Universidade Federal do Paraná. 100p.

Milani JEF, Roderjan CV, Kersten RA, Galvão F (2013) Fenologia vegetativa e reprodutiva de Schinus terebinthifolius Raddi (Anacardiaceae) em um fragmento de Floresta Ombrófila Mista Aluvial-Araucária (PR). Estudos de Biologia, 35(85):135-142.

Milani JEF (2017) Autoecologia de espécies arbóreas de uma floresta aluvial: fenologia e crescimento. Tese, Setor de Ciências Agrárias, Universidade Federal do Paraná. 92p.

Morellato LPC, Alberton B, Alvarado ST, Borges B, Buisson E, Camargo MGG, Cancian LF, Carstensen DW, Escobar DFE, Leite PTP, Mendoza I, Rocha NMWB, Soares NC, Silva TSF, Staggemeier VG, Streher AS, Vargas BC, Peres CA (2016) Linking plant phenology to conservation biology. Biological Conservation, 195(2016):60-72. doi: 10.1016/j.biocon.2015.12.033

Morellato LPC, Romera EC, Talora DC, Takahashi A, Bencke CC, Zipparro VB (2000) Phenology of Atlantic Rain Forest trees: a comparative study. Biotropica, 32(4):811-823. doi: https://doi.org/10.1111/j.17447429.2000.tb00620.x

Pirani FR, Sanchez M, Pedroni F (2009) Fenologia de uma comunidade arbórea em cerrado sentido restrito, Barra do Garças, MT, Brasil. Acta Botanica Brasilica, 23(4):10961109.

Rego GM, Lavaronti OJ (2007) Atividades fenológicas de imbuia (Ocotea porosa (Nees et Martius ex Ness) em áreas de Floresta Ombrófila Mista, no estado do Paraná. In: Rego GM, Negrelle RRB, Morellato LPC. Fenologia: ferramenta para conservação, melhoramento e manejo de recursos vegetais arbóreos. Colombo: Embrapa Florestas.

Rodríguez MI, Gajardo C, Solís F (2010) Escalas de compromiso funcional y de movimientos involuntarios en extremidades superiores en niños con trastornos de movimiento de tipo extrapiramidal. Rehabilitación, 44(4):336-344.

Santana WMS, Silva-Mann R, Ferreira RA, Arrigoni-Blank MF, Blank A, Poderoso JCM (2009) Morfologia de flores, frutos e sementes de pau-pombo (Tapirira guianensis Aublet. -Anacardiaceae) na região de São Cristóvão, SE, Brasil. Scientia Forestalis, 37(81):47-54.

Santos PL, Ferreira RA (2013) Fenologia de Tapirira guianensis Aubl. (anacardiaceae) no município de São Cristóvão, Sergipe. Revista Árvore, 37(1):129-136. doi: http://dx.doi.org/10.1590/S010067622013000100014 
Soares RV, Batista AC, Tetto AF (2015) Meteorologia e climatologia florestal. Curitiba, 215p.

Talora DC, Morellato LPC (2000) Fenologia de espécies arbóreas em floresta de planície litorânea do sudeste do Brasil. Revista Brasileira de Botânica, 23(1):13-26. doi: http://dx.doi.org/10.1590/S0100-84042000000100002 